\title{
Changing patterns of home visiting in the North of England
}

\author{
JOHN WHEWELL, GEOFFREY N MARSH, R ANGUS MCNAY
}

\begin{abstract}
The visiting habits of general practitioners in the north of England in 1969 and in 1980 have been compared. During this period overall visiting was reduced by $41 \%$. The reduction was most pronounced in repeat visits, particularly to children. There was a greater reduction in visits to patients with respiratory disease than to those with other illness. The reduction was least in visits to patients over the age of 65 . New visits requested by patients were reduced by $31 \%$, but the general practitioner still considered that about the same percentage of patients could have attended the surgery as in 1969 .

The reasons for these differences include flexible appointment systems, improved efficiency, better organisation of the surgery, and more flexible arrangements for certification of absence from work. Though total workload (as measured by the number of consultations with patients) has diminished, general practice has changed, being more concerned with prevention, chronic disease, and vocational training.
\end{abstract}

\section{Introduction}

Anxiety is often expressed that British general practitioners are not as willing as they were to make home visits to patients. Visiting of the elderly in particular has been considered inadequate. ${ }^{1}$ Paradoxically, many general practitioners believe that home visits are still an essential and important component of their practice. ${ }^{2}$ Inspired by the shortage of hard data we studied home visits in northern England in two weeks in 1980 and compared the findings with those of an almost identical study in $1969 .^{3}$

\section{Method}

In both studies all fellows, members, and associates of the north of England faculty of the Royal College of General Practitioners were invited to take part and asked to recruit colleagues who were not in the college. A total of 190 doctors in 1969 and 202 in 1980 recorded details of all their home visits from Monday to Friday in the last week of November and first week of December. Surgery consultations

\section{Middlesbrough, Cleveland TS1 2NX}

JOHN WHEWELL, MB, FRCGP, general practitioner

Stockton-on-Tees, Cleveland TS20 1AN

GEOFFREY N MARSH, MD, FRCGP, general practitioner

Northern Regional Health Authority

R ANGUS MCNAY, BSC, FSS, regional statistician

Correspondence to: Dr John Whewell. were also recorded, but weekend work was excluded. These dates were chosen because it was thought to be a period when holidays and epidemics were unlikely to interfere with the results.

The figure shows the questions asked on the form completed for each visit by doctors in the 1980 study; it is almost identical to that used in the 1969 study. The doctors gave the name, age, and sex of

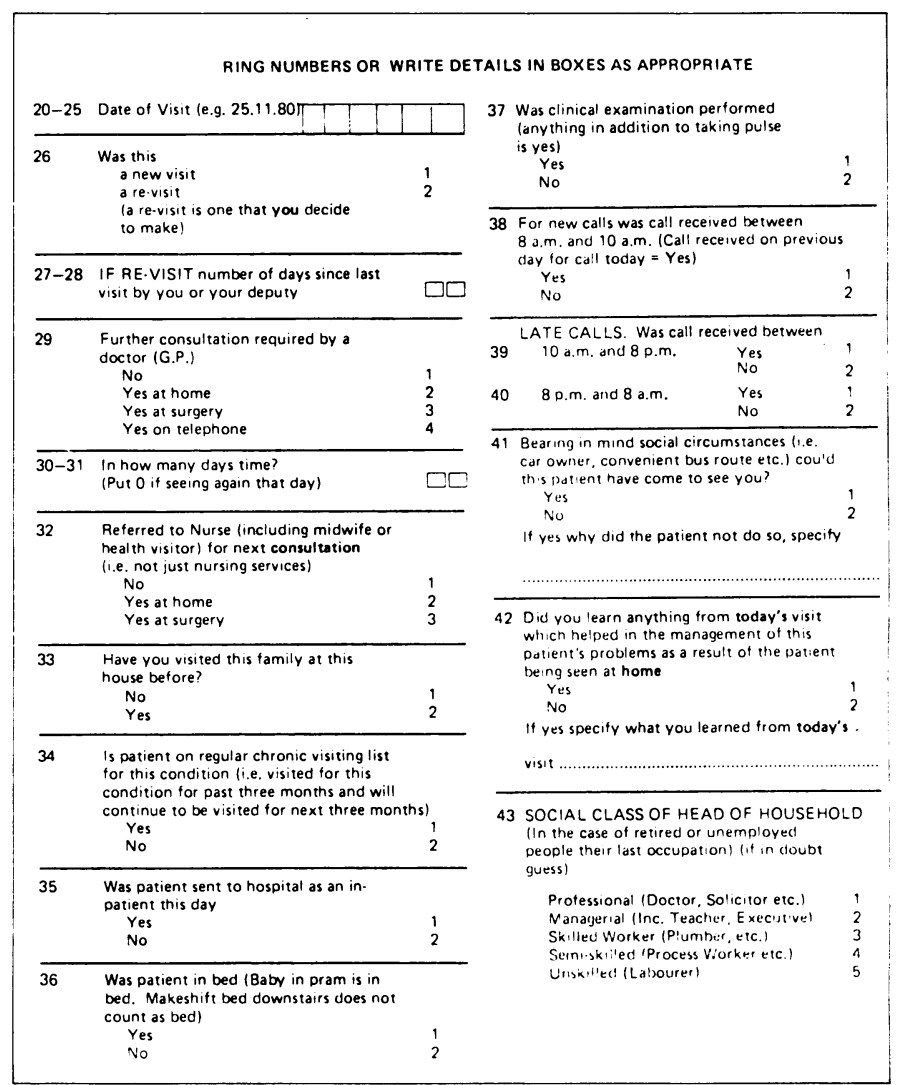

Form completed by doctors for home visits during study period 1980. First part of form (not shown) left for details of patient and office data.

patients visited and gave a diagnosis, which was subsequently classified according to the International Classification of Diseases. The doctors were asked to state whether it was the first visit made to the patient for that illness (new visit) or a repeat visit, further classified according to whether it was a repeat visit for an acute or a chronic illness (a condition for which the patients had been visited in the past three months and would continue to be visited for the next three months). They were asked to give details of the time of the request for the visit, whether a follow up consultation with a nurse had been arranged, and whether the doctor considered a home visit had been necessary. 


\section{Results}

Table I gives details of surgery consultations and home visits undertaken by the doctors in the two study periods. There was a $23 \%$ reduction in surgery consultations from 1969 to 1980 and a considerable reduction in all types of home visit. The ratio of surgery consultations to home visits was $3 \cdot 1$ to 1 in 1969 and $4 \cdot 1$ to 1 in 1980 .

There was a great variation among practices in both surveys. The rate of visiting could be related only to those 40 practices where each member took part, but of these practices in 1980 the upper quartile was conducting twice as many surgery consultations per 1000 patients and four times the number of home visits per 1000 patients than the lower quartile.

TABLE I-Mean number of surgery consultations and home visits conducted by general practitioners in 1969 and 1980. Figures number per doctor per day

\begin{tabular}{|c|c|c|c|}
\hline & 1969 & 1980 & $\%$ Reduction \\
\hline $\begin{array}{l}\text { Surgery consultations } \\
\text { Home visits } \\
\text { New } \\
\text { Repeat (acute) } \\
\text { Repeat (chronic) }\end{array}$ & $\begin{array}{ll} & 28 \cdot 5 \\
4 \cdot 5 & 9 \cdot 1 \\
2 \cdot 8 & \\
1 \cdot 8 & \end{array}$ & \begin{tabular}{lr|} 
& $21 \cdot 9$ \\
$3 \cdot 1$ & $5 \cdot 4$ \\
$1 \cdot 2$ & \\
$1 \cdot 1$ &
\end{tabular} & $\begin{array}{l}23 \\
41 \\
31 \\
57 \\
39\end{array}$ \\
\hline
\end{tabular}

TABLE II-Mean number of visits (new and repeat) made by each doctor over 10 day study period by age of patient

\begin{tabular}{|c|c|c|c|}
\hline \multirow{2}{*}{$\begin{array}{l}\text { Age of } \\
\text { patient } \\
\text { (years) }\end{array}$} & \multicolumn{2}{|c|}{ Study } & \multirow{2}{*}{ \%Decrease } \\
\hline & 1969 & 1980 & \\
\hline \multicolumn{4}{|c|}{ New visits } \\
\hline $\begin{array}{c}<1 \\
1-4 \\
5-14 \\
15-44 \\
45-64 \\
65 \geqslant\end{array}$ & $\begin{array}{r}5 \cdot 7 \\
5 \cdot 2 \\
8 \cdot 1 \\
10 \cdot 2 \\
8 \cdot 5 \\
9 \cdot 1\end{array}$ & $\begin{array}{r}1.4 \\
2.7 \\
5.2 \\
6 \cdot 2 \\
3.7 \\
10.6\end{array}$ & $\begin{array}{l}75 \\
48 \\
36 \\
39 \\
56 \\
16^{*}\end{array}$ \\
\hline \multicolumn{4}{|c|}{ Repeat visits } \\
\hline $\begin{array}{c}1 \\
1-4 \\
5-14 \\
15-44 \\
45-64 \\
65 \geqslant\end{array}$ & $\begin{array}{r}2 \cdot 9 \\
1.5 \\
2 \cdot 3 \\
6 \cdot 1 \\
10 \cdot 2 \\
20 \cdot 8\end{array}$ & $\begin{array}{r}0 \cdot 4 \\
0.4 \\
0 \cdot 6 \\
2 \cdot 2 \\
3 \cdot 8 \\
15 \cdot 8\end{array}$ & $\begin{array}{l}86 \\
73 \\
74 \\
64 \\
63 \\
24\end{array}$ \\
\hline
\end{tabular}

* Increase.

TABLE III-Mean number of home visits made by each doctor over 10 day study period by disease category*

\begin{tabular}{lrr}
\hline \multicolumn{1}{c}{ Disease category* } & 1969 & 1980 \\
\hline Respiratory & $34 \cdot 0$ & $14 \cdot 2$ \\
Circulatory & $10 \cdot 0$ & $7 \cdot 1$ \\
Nervous and special sense & $6 \cdot 1$ & $4 \cdot 9$ \\
Gastrointestinal & $5 \cdot 8$ & $4 \cdot 6$ \\
Infectious & $4 \cdot 5$ & $2 \cdot 9$ \\
Musculoskeletal & $4 \cdot 4$ & $3 \cdot 6$ \\
Trauma & $3 \cdot 7$ & 1.9 \\
Neoplasms & $2 \cdot 9$ & $2 \cdot 7$ \\
Psychiatric & $2 \cdot 6$ & $3 \cdot 1$ \\
Pregnancy & $2 \cdot 6$ & $1 \cdot 7$ \\
\hline
\end{tabular}

* International Classification of Diseases.

When home visits were analysed by age of patient (table II) there was a reduction over the study periods in all groups, with the exception of new visits to patients over 65 , which increased by $16 \%$. The reduction in home visits was most pronounced in children, particularly in infants under 1 year.

Table III shows mean number of visits by disease classification. In both 1969 and 1980 respiratory diseases were the most common diagnosis in patients visited at home. The mean number of visits per doctor over a 10 day study period, however, fell from 34 in 1969 to 14 in 1980. The number of visits fell for every other disease except psychiatric illnesses, where the mean rose from $2 \cdot 6$ to $3 \cdot 1$ : this rise was largely due to the increase in visits to patients with dementia.

A total of $14.8 \%$ of all patients visited at home were referred to a nurse for consultation follow up in 1969; this fell to $6.7 \%$ in 1980 .

Monday was the busiest day of the week, with roughly one quarter of all home visits in both study periods being conducted on this day. The proportion for other days of the week varied from $16 \%$ to $19 \%$ and were the same for both periods.

When requests for a home visit were analysed by the time of the call (table IV), numbers at all times fell, except those between $8 \mathrm{pm}$ and $8 \mathrm{am}$, which rose.

In a total of $78.4 \%$ of all home visits in 1980 the doctor had visited the family in that house before.

Despite the absolute fall in the number of home visits, doctors in $\mathbb{D}$ both study periods thought that about one quarter of patients visited at home (new visits) could have come to the surgery $(27 \%$ in 1969 and $25 \%$ in 1980) (table V).

TABLE IV-Mean number of calls received for new visit by each doctor* over study period by time of receipt of call

\begin{tabular}{lrr}
\hline Time & 1969 & 1980 \\
\hline $0800-1000$ & 37.4 & 22.9 \\
$1001-2000$ & 6.7 & 4.7 \\
$2001-0759$ & 1.4 & 1.7 \\
Not specified & 1.7 & 0.9 \\
\hline * Excludes doctors who & used \\
deputising services. & &
\end{tabular}

TABLE $\mathrm{V}$-Percentage of home visits judged unnecessary by doctors (patient could have come to surgery) by age of patient

\begin{tabular}{lcc}
\hline Age (years) & 1969 & 1980 \\
\hline$<1$ & 55 & 37 \\
$1-4$ & 35 & 37 \\
$5-14$ & 35 & 35 \\
$15-44$ & 28 & 27 \\
$45-64$ & 21 & 24 \\
$65 \geqslant$ & 13 & 13 \\
All patients & 27 & 25 \\
\hline
\end{tabular}

\section{Discussion}

The data were collected for only 10 working days in each of $\overrightarrow{\overrightarrow{0}}$ the two years from about 200 self selected doctors. Accordingly, it is not necessarily representative of the whole working year or of all doctors in the northern region. Nevertheless, a mean of 5.4 home visits and 21.9 surgery consultations per doctor per day appears to confirm some general practitioners' feelings that they are not always very busy and are certainly under less $\frac{\sigma}{3}$ pressure than they were in 1969. (The results show a $41 \%$. reduction in home visiting, with newly requested visits reduced by $31 \%$, acute repeat visits by $57 \%$, and repeat visits for chronic illness by $39 \%$.) A concomitant $23 \%$ reduction in attendances at 윽 the surgery indicates that the reduction in home visits has not led $N$ to more surgery attendances. Studies by Intercontinental $D$ Medical Statistics (a commercial organisation collecting data 을 on workload and prescribing practices from general practice) $\mathrm{N}$ show a similar reduction in home visits of $43 \%$ during the 오 same period. ${ }^{4}$

There was a considerable reduction in both new visits and repeat visits in all age groups except the over $65 \mathrm{~s}$ where new calls actually rose by $16 \%$ and repeat visits reduced by only $24 \%$ compared with around $70 \%$ for all other age groups.

To what extent are these changes due to demographic $\frac{T}{0}$ changes in the population of northern England? The average $\frac{\overrightarrow{\mathbb{D}}}{\mathbb{P}}$ general practitioner's list size in northern England dropped $\frac{\rho}{\mathbb{Q}}$ from 2529 in 1969 to 2291 in 1980 , a reduction of $9 \%$. The $\varrho$ 1971 and 1981 censuses may be used to give some indication of population change during the period between the two surveys. o In the northern region the number of children under 1 year of age dropped by $21 \%$ and the number aged from 1 to 4 years by $25 \%$. This undoubtedly accounts for some of the decrease 
in home visiting of children. On the other hand, home visiting of patients aged over 65 decreased by $12 \%$ overall, although the number of people of that age increased by $13 \%$. Thus although changes in population may have influenced the results they are obviously not completely responsible for the reduction in visiting.

The 1969 study included neither trainees nor doctors over 60 who had retired (in order to claim pension) and been reemployed after 24 hours. Inclusion of these groups in the 1980 study did not significantly influence the results. Indeed, close analysis showed that doctors who had been qualified 30 years or more conducted more visits and surgery consultations than the rest. The number of trainees taking part in the second study was so small that their exclusion from the survey produced no significant differences.

So why have home visits been reduced so much? Firstly, more people have cars to transport either themselves or members of their family and sometimes neighbours and friends to the surgery. Despite an increased centralisation of surgeries associated with the swing to group practice, their siting has usually been as convenient as possible for access by public transport. Flexible appointment systems, improved efficiency, and better organisation of the surgery all make attendances there easier and less time consuming and allow "same day" appointments for acute minor illness (flu, earache, abdominal pain, etc). Intermittent campaigns by the Department of Health and Social Security on television and in the newspapers have encouraged more surgery attendances. The more flexible arrangements for certification of absence from work also helped. A major factor in reducing the number of home visits has probably been the attempt by doctors, and reception staff under their instruction, to minimise what they perceive to be unnecessary home visits. In some practices a doctor "vets" all requests for home visits, especially those made after $10 \mathrm{am}$; this almost certainly accounts for the considerable variation in the number of home visits from one practice to another.

In 1969 GPs considered that $27 \%$ of patients requesting new visits could have come to the surgery, so a reduction in the number of "unnecessary" home visits might have been expected. Despite the fact that the number of new visits has fallen by $31 \%$, however, GPs still consider $25 \%$ of new home visits to have been unnecessary. The gap between their expectations and those of the patient is almost as large as ever.

The number of home visits to children has undoubtedly decreased; has it gone too far and put the health of children at risk? We know of no evidence that the mortality or health of infants is related to the amount of home visiting by GPs. Nevertheless, we feel a little anxious about this, particularly with regard to children in low social class homes. In 1969 general practitioners thought that $55 \%$ of children visited at home should have come to the doctor, so' presumably most reduction could be expected in this age group. This increases the necessity to ensure that the general practitioner's appointment system is sufficiently flexible to cope with sick children, "same day" appointment being essential.

The reduction in the number of home visits to the elderly is less than the reduction in visits to other age groups. Visits to the elderly comprised $34 \%$ of total visits and $68 \%$ of repeat visits; this is in line with the findings of a recent survey. ${ }^{5}$ Many of the patients with chronic illness were in this age group and the number of visits to these patients showed a corresponding reduction. Though visiting the chronically ill has a place in the surveillance of many of the disabling diseases we cannot cure, many elderly patients now receive more help at home from home helps and social workers, supervisory wardens, etc, and a far greater number now visit day centres and workshops than in the late 1960s. The "social" visit by the general practitioner is not, therefore, as important as it used to be. Caring for patients with chronic illness is essentially a team commitment, but with the reduction of patients referred to nurses from $14.8 \%$ in 1969 to $6.7 \%$ in 1980 there is obviously a need to reassess and revitalise primary health care team work.
In $78 \%$ of the total visits carried out in 1980 the GP had visited that family in that house before. Bearing in mind family mobility and the fact that some doctors would be deputising for absent partners and others may not have been in the practice for very long, GPs have a remarkable knowledge of their patients' homes. This will probably change drastically and the office orientated style of care so characteristic of North American medicine-and much criticised by the patients there-could well become the pattern in Britain unless a halt is called to this rapid decrease in home visiting.

Total workload as measured by the number of consultations with patients has certainly reduced in the north of England, but this is a poor indicator of effort; what transpires in the consultation is a much more important factor. General practice is responsible for more chronic illness than it was 11 years ago: it takes more time to review adequately a patient with diabetes or hypertension or to counsel a patient with a smoking problem than to treat a child with a cold. General practice is more concerned with preventive medicine than it was, and the advent of vocational training for general practice absorbs considerable time for many GPs. General practice is changing it has changed considerably in the 11 years covered by these surveys and no doubt will change even more in the future.

We thank the general practitioners who took part in both these surveys, the Northern Regional Health Authority for their financial support, and Mrs Kathleen McFarlane for her help with the analyses and for administering the 1980 survey.

\section{References}

'National Old People's Welfare Council. Age concern on health. $\mathcal{F}$ Coll Gen Pract 1973;23:615.

2 Pereira Gray DJ. Feeling at home. $\mathcal{f} R$ Coll Gen Pract 1978;28:6-17.

${ }^{3}$ Marsh GN, McNay RA, Whewell J. Survey of home visiting by general practitioners in North East England. Br Med f $1972 ; \mathrm{i}: 487-92$.

4 Intercontinental Medical Statistics Limited. Medical data index 1981 London: Intercontinental Medical Statistics Limited, 1981.

5 Sawyer L, Archer S. Changes in home visiting and weekend cover: the patient's view. $\mathrm{Br}$ Med $\mathcal{F} 1982 ; 284: 1531-4$.

(Accepted 16 February 1983)

\section{Clinical curio: acidosis and hypoglycaemia in malaria}

Falciparum malaria may present a confusing picture as the following case illustrates.

A 19 year old Zambian Bantu woman was admitted to Wusikili Hospital, Kitwe, on 3 April 1980 complaining of headache and chest pain. She was eight months' pregnant. Her temperature was $36 \cdot 2^{\circ} \mathrm{C}$, and she was pale, jaundiced, and dyspnoeic. A sinus tachycardia was present, and her blood pressure was $130 / 80 \mathrm{~mm} \mathrm{Hg}$. A blood slide showed numerous ring forms of Plasmodium falciparum and scanty gametocytes. Results of investigations were: haemoglobin concentration $5.0 \mathrm{~g} / \mathrm{dl}$, white blood cell count $31 \cdot 1 \times 10^{9} / 1$, with $74 \%$ polymorphs and $26 \%$ lymphocytes, and platelet count $198 \times 10^{9} / 1$. Haemoglobin electrophoresis showed that she had normal haemoglobin. Serum biochemical values were: urea $18.4 \mathrm{mmol} / 1(111 \mathrm{mg} / 100 \mathrm{ml})$, sodium $122 \mathrm{mmol} / 1(\mathrm{mEq} / \mathrm{l})$, potassium $4.4 \mathrm{mmol} / 1(\mathrm{mEq} / \mathrm{l})$, and glucose $0.90 \mathrm{mmol} / 1(16.2 \mathrm{mg} / 100 \mathrm{ml})$. The arterial blood $\mathrm{pH}$ was 6.86 with a po $^{2}$ of $105.2 \mathrm{mmHg}, \mathrm{pco}^{2}$ of $14.0 \mathrm{~mm} \mathrm{Hg}$, and standard bicarbonate of $2.9 \mathrm{mmol} / \mathrm{l}(\mathrm{mEq} / \mathrm{l})$.

Malaria complicated by sepsis was suspected, and the patient was treated with transfusion, intravenous chloroquine, and ampicillin. Sodium bicarbonate was infused to try to correct the acidosis. Despite this the patient's condition deteriorated, and she died 14 hours after admission. Post mortem examination showed widespread deposition of malarial pigment in the internal organs, but no sign of sepsis or any other intrinsic disease.

A search for further information on the mechanisms implicated in the production of hypoglycaemia and acidosis in malaria has yielded negative results. - C W S FISHER, locum consultant physician, Aylesbury. 